REJ - Revista de Estudios de la Justicia - No 4 - Año 2004

\title{
EL DERECHO PENAL CHILENO ANTE EL ESTATUTO DE ROMA
}

\author{
Antonio Bascuñan Rodríguez*
}

1. Planteamiento; 2. Problemas básicos de la parte especial: 2.1 Los deberes de punición del Derecho Internacional Público; 2.2 Los deberes de punición del Estatuto de Roma; 2.3 La insuficiencia del derecho penal chileno; 2.4 Opciones de técnica legislativa; 2.5 Problemas fundamentales de la Parte Especial del Código Penal chileno; 2.6 Problemas fundamentales de los crimenes de derecho internacional. 3. Problemas básicos de la parte general.

\section{PLANTEAMIENTO}

La eventual aprobación y ratificación por parte del Estado de Chile del Estatuto de Roma sobre la Corte Penal Internacional plantea diversos problemas jurídicos de interés. El objeto de esta contribución es el análisis de un ámbito específico de problemas, a saber, los desafíos que ello presenta al derecho penal chileno.

La incorporación de Chile al Estatuto de Roma implica el reconocimiento de la jurisdicción de la Corte Penal Internacional, lo cual incluye su competencia para conocer y juzgar comportamientos sometidos a la jurisdicción de los tribunales chilenos. El derecho vinculante para la Corte Penal Internacional es, preferentemente, el establecido en el Estatuto de Roma (art. 21-1-a). Luego, el reconocimiento del Estatuto de Roma implica la aceptación de un cuerpo de derecho penal sustantivo como derecho aplicable a comportamientos sujetos a la jurisdicción chilena, si esos comportamientos son juzgados por la Corte Penal Internacional.

La incorporación de Chile al Estatuto de Roma no significa, por cierto, que las normas penales establecidas en dicho Estatuto adquieran el carácter de derecho penal aplicable por tribunales chilenos. El Estatuto es en esto inequívoco: las normas de su Parte Especial determinan la competencia de la Corte Penal Internacional ratione materiae (art. $5^{\circ}$ ), y las reglas y principios de la Parte General del Estatuto son derecho aplicable para la Corte (art. 21). Así pues, respecto de todo el universo de casos sometidos alternativamente a la jurisdicción de los tribunales chilenos y a la jurisdicción de la Corte Penal Internacional existe una duplicidad de regulaciones penales sustantivas: el derecho penal chileno y el derecho penal sustantivo contenido en el Estatuto de Roma.

Ciertamente, se puede sostener que ambos regímenes jurídicos son complementados, al menos subsidiariamente, por los principios del derecho internacional. Esto es explícito, tratándose del Estatuto de Roma (art. 21-1b), y puede sostenerse como consecuencia del principio de la incorporación del derecho internacional al derecho interno, tratándose del derecho chileno. Aquí se encontraría un común denominador. Sin duda que éste es un aspecto importante de las relaciones entre ambos órdenes normativos convencionales. Pero no obsta a la existencia de uno y otro como regímenes penales

\footnotetext{
* Profesor de Derecho Penal, Universidad de Chile, Universidad Adolfo Ibáñez.
} 
Bascuñán - El derecho penal chileno ante el Estatuto de Roma

paralelos. Dándose este paralelismo, ¿cómo podría el Estatuto de Roma presentar desafíos al derecho penal chileno?

La pregunta tiene al menos cuatro respuestas posibles. Dos de ellas me parecen principales; las otras dos, tienen a mi parecer un carácter más bien secundario.

Los dos sentidos más importantes en los que se puede decir que el Estatuto de Roma presenta desafíos al derecho penal chileno son los siguientes:

(a) El Estatuto de Roma pudiera contener disposiciones que impusieran al Estado de Chile, como Estado parte, algún deber de adecuación del derecho penal interno. Si ese fuera el caso, allí se encuentra una fuente de desafíos.

(b) Como es bien sabido, la jurisdicción de la Corte Penal Internacional opera bajo el principio de complementariedad, es decir, subsidiariamente a la jurisdicción de los Estados (art. $\left.1^{\circ}\right)$. Conforme al Estatuto, la admisibilidad del caso ante la Corte Penal Internacional depende, entre otras condiciones, de que no se encuentre o no haya estado sometido ante los tribunales de un Estado que tenga jurisdicción sobre él. Esta causa de inadmisibilidad opera con tal que el Estado tenga o haya tenido la genuina voluntad y la habilidad de llevar adelante la investigación y prosecución (arts. 17-1 y 20-3). En términos generales, las controversias que puede originar el examen de admisibilidad por esta causa giran en torno a la buena fe con que haya intervenido o se encuentre interviniendo el Estado que ejerció o ejerce jurisdicción. Por esta razón, no se encuentra explícitamente regulado a propósito de la inadmisibilidad el supuesto en el que hubiere sentencia absolutoria o algún equivalente procesal anticipado en razón de atipicidad del comportamiento investigado o acusado. No obstante, todo el sistema de ejercicio complementario de la jurisdicción de la Corte Penal Internacional descansa en el hecho de la irrelevancia de ese supuesto para la cuestión de admisibilidad. Hasta donde alcanzo a ver, esto puede afirmarse por dos vías: (aa) Por una parte, puede sostenerse que un Estado cuya potestad punitiva se encuentra sometida al principio de legalidad y en el cual no existe una disposición legal que describa como delito el hecho constitutivo de crimen bajo el Estatuto de Roma, es un Estado que carece de jurisdicción sobre el crimen, en el sentido del Estatuto, y por lo tanto a su respecto no opera la deferencia debida en virtud del principio de complementariedad; (bb) Por otra parte, puede sostenerse que el principio de complementariedad opera bajo el principio del Derecho Penal Internacional de dedere aut indicare (entregar o procesar), que no reconoce al principio de legalidad como causa de exoneración de la obligación de entregar. Así entendida la cuestión de admisibilidad, es en el interés del propio Estado de Chile en ejercer su jurisdicción criminal en este ámbito de delitos donde se encuentra la fuente del desafío que el Estatuto de Roma presenta al derecho penal interno.

Además de los dos aspectos anteriores, puede mencionarse como aspectos secundarios en los que el Estatuto de Roma puede ofrecer desafíos al derecho chileno los siguientes:

(c) Es claro que el Estatuto de Roma no tiene el carácter de una codificación del Derecho Internacional Penal. Como se ha dicho, la función de sus normas punitivas es tan solo la de definir convencionalmente la jurisdicción de la Corte ratione materiae. Expresamente, el Estatuto declara que esta fijación no limita ni prejuzga en sentido alguno las reglas existentes o en desarrollo del derecho internacional para efectos distintos 
de la jurisdicción de la Corte Penal Internacional (art. 10). Con todo, el Estatuto tiene significación para el Derecho Penal Internacional como punto de apoyo institucional para la demostración de la vigencia de las normas de comportamiento que se estima imponen a los Estados deberes de punición o al menos el deber de entregar o juzgar. Dicho de modo plástico: si bien las normas del Estatuto no limitan negativamente el ámbito del Derecho Penal Internacional, sí permiten demostrar positivamente su ámbito mínimo indiscutible. Desde este punto de vista, el Estatuto de Roma constituye un reforzamiento de los desafíos que el Derecho Penal Internacional presenta al derecho penal chileno. Si el Estado de Chile quiere cumplir con los deberes internacionales de punición, o ejercer efectivamente su jurisdicción en este ámbito con preferencia a la intervención de tribunales extranjeros, entonces es razonable tomar en consideración al Estatuto de Roma como indicio de la medida a ser satisfecha por el derecho penal interno.

(d) Finalmente, en el orden de prelación del derecho aplicable por la Corte Penal Internacional, el tercer y último lugar lo ocupan los principios de los sistemas jurídicos nacionales, incluyendo el derecho del país que normalmente ejercería jurisdicción sobre el delito, con tal que esos principios no sean inconsistentes con el Estatuto y con el derecho internacional. La congruencia con el Estatuto de Roma es, pues, condición de la aplicabilidad (subsidiaria) del derecho chileno por la Corte Penal Internacional. Aquí se encuentra otra fuente de desafíos.

Como todo derecho penal sustantivo occidental, el derecho penal del Estatuto de Roma se compone de una Parte Especial, conformada por normas que tipifican supuestos de hecho, y de una Parte General, conformada por reglas y principios que extienden esos supuestos (participación, tentativa) o bien que reconocen causas de exclusión de la punibilidad. La Parte Especial se encuentra en los arts. $5^{\circ}$ a $8^{\circ}$ y en el art. 70; la Parte General, en los arts. 25 a 33. En lo que sigue me referiré primero a los problemas básicos de la Parte Especial, para luego considerar los problemas básicos de la Parte General.

\section{PROBLEMAS BÁSICOS DE LA PARTE ESPECIAL}

\subsection{Los deberes de punición del Derecho Internacional Público}

El Derecho Internacional Público, particularmente en su rama del Derecho Internacional de los Derechos Humanos ha formulado deberes de protección, es decir, deberes dirigidos a los Estados para que dispensen protección (y no solo respeto) a ciertos intereses, a partir de los cuales se pretende deducir deberes de punición, es decir, deberes dirigidos a los Estados para que impongan una pena a los actos de afectación de los intereses que deben proteger. La cuestión de una posible relación entre deberes de protección y deberes de punición tampoco es ajena a la jurisprudencia constitucional alemana. En otro lugar me he pronunciado en contra de la postulación de una relación de derivación de deberes de punición a partir de deberes de protección. No es del caso entrar aquí en esta cuestión, pues lo que caracteriza al Derecho Penal Internacional es la afirmación directa (y no por derivación) de deberes de punición. Esto se produce por dos vías: mediante el deber de establecer una norma punitiva o mediante el deber de entregar o juzgar (dedere aut iudicare). En adelante me concentraré en el primer sentido. 
Bascuñán - El derecho penal chileno ante el Estatuto de Roma

Un deber de punición puede ser simple o cualificado. Al deber de punición simple lo denomino "deber de incriminación". Los deberes de punición cualificados los denomino "deberes de tipificación", que a su vez pueden ser de dos clases, deberes moderados de tipificación o deberes extremos de tipificación. El fundamento de esta distinción, que se encuentra en una aplicación de la teoría de los actos de habla (speech acts) a las relaciones entre enunciados normativos y actos de establecimiento de normas, ya lo he expuesto en otra parte. Aquí me limitaré a señalar que el deber de incriminación se satisface con una congruencia en el nivel de las normas (Normen), sin exigir además congruencia en el nivel de las disposiciones (Vorscbriften); aquello a que se refiere el deber de punición como acto constitutivo de delito debe ser reconocible como ámbito de referencia del supuesto de hecho de la norma punitiva interna. Que el lenguaje sea el medio de constatación de la congruencia y la incongruencia entre uno y otro ámbito de referencia, es algo inevitable. Lo crucial es que ningún modo de existencia pragmática de los enunciados normativos es determinante en esta relación. Por contraste, los deberes de tipificación presuponen un modo de existencia pragmática del deber de punición, que es relevante para su destinatario. En su formulación extrema, un deber de tipificación exige del Estado la transcripción en el nivel del derecho interno de (al menos) un enunciado normativo prefijado convencionalmente. En su formulación moderada, un deber de tipificación exige del Estado la configuración de un supuesto de hecho sistemáticamente autónomo, lo que razonablemente incluye una denominación individualizada congruente con el fin de protección del deber de punición.

Qué clase de deber de punición consagra el Derecho Penal Internacional respecto de cada crimen internacional, ésa es una cuestión interpretativa, o sea, contingente. Como es obvio, el Derecho Penal Internacional consuetudinario o de principios, sólo puede contener deberes de incriminación. En cambio, el Derecho Penal Internacional convencional puede contener deberes de tipificación, tanto extremos como moderados. Sobre el punto, en otro lugar he sostenido que debe siempre preferirse la interpretación de los deberes de punición como deberes de incriminación, y de los deberes de tipificación como deberes moderados, por lo que la carga de la prueba argumentativa la tiene siempre la interpretación que conlleva más exigencias. Asumo aquí el mismo principio interpretativo.

Una vez efectuadas estas distinciones, cabe preguntarse: ¿consagra deberes de punición el Estatuto de Roma? Y en caso afirmativo, ¿de qué clase?

\subsection{Los deberes de punición del Estatuto de Roma}

El Estatuto de Roma sí consagra un deber de punición, pero con la finalidad más inesperada. Lo esperable de un cuerpo de normas punitivas de los crímenes más graves del derecho internacional sería que impusiera a los Estados parte deberes de punición de estos crímenes. Ése no es el caso. En el Estatuto no existen deberes de punición de los crímenes de agresión, genocidio, contra la humanidad ni de guerra. El único deber de punición del Estatuto se encuentra en su art. 70-(4)-(a), en el cual impone a los Estados parte el deber de incorporar en su derecho penal interno normas que sancionen adecuadamente los delitos contra la administración de justicia a que se refiere el propio art. 70-(1).

Tratándose de los crímenes de derecho internacional, el Estatuto se conforma con el establecimiento de la jurisdicción de la Corte Penal Internacional bajo el principio 
REJ - Revista de Estudios de la Justicia - No 4 - Año 2004

de complementariedad. Si el Estado de Chile se encuentra o no sujeto a un deber de punición respecto de estos delitos, eso es algo que debe resolverse atendiendo al Derecho Penal Internacional, y no al Estatuto. En todo caso, si así se lo afirma, la regulación del Estatuto brinda una medida para la evaluación del cumplimiento satisfactorio de ese deber.

Desde el punto de vista de las obligaciones internacionales convencionales contraídas por el Estado de Chile, existen deberes de incriminación inequívocos en lo que respecta al genocidio y a las infracciones graves a los cuatro Convenios de Ginebra y su Protocolo I. A estas alturas de la evolución experimentada por el Derecho Internacional Humanitario, también debe considerarse como delitos con el estatus de infracciones graves las violaciones al art. $3^{\circ}$ común de los cuatro Convenios y a su Protocolo II. Tratándose de los crímenes contra la humanidad, no existe una base convencional semejante. Por cierto, algunos casos específicos de crímenes contra la humanidad constituyen crímenes internacionales, respecto de los cuales existen deberes convencionales de punición, como lo son la tortura, la desaparición forzada de personas, la esclavitud y el proxenetismo transnacional. Pero esto es en tanto atentados singulares contra derechos humanos. Lo que falta es el deber convencional de su tratamiento jurídico-penal como crímenes contra la humanidad, bajo la consideración de su carácter sistemático y/o masivo. Bajo esta consideración, el deber de punición referido a ellos tiene carácter consuetudinario y/o de principio.

En suma, tratándose de los crímenes más graves del derecho internacional penal, el Estatuto de Roma no impone deberes de punición. En consecuencia, el desafío que el Estatuto de Roma plantea al derecho penal chileno tiene lugar en el nivel del principio de complementariedad, o en el nivel de su función de apoyo institucional para determinar la medida mínima de satisfacción de los deberes de punición del derecho penal internacional, ya sean convencionales o no convencionales.

\subsection{La insuficiencia del derecho penal chileno}

En el derecho penal chileno no existen normas que configuren supuestos de hecho correlativos a los tipos configurados en los arts. $6^{\circ}$ (genocidio), $7^{\circ}$ (crímenes contra la humanidad) y $8^{\circ}$ (crímenes de guerra) del Estatuto de Roma. Por lo tanto, en la medida que se sostenga la existencia de deberes de tipificación relativos a estos delitos en el Derecho Internacional Penal exigibles al Estado de Chile, éste se encontraría en incumplimiento de esos deberes. Esto es indiscutible.

La cuestión difícil de esclarecer es cuál sea la situación del derecho penal chileno bajo la consideración de esos deberes de punición como deberes de incriminación.

En términos generales, respecto de cada categoría de crímenes del Estatuto de Roma uno puede distinguir tres ámbitos bien diferenciados de congruencia del derecho penal chileno con el derecho penal internacional:

(a) existe un ámbito nuclear, en el cual el derecho penal chileno satisface inequívocamente el mandato de punición, al menos en lo que respecta a la punibilidad del comportamiento; éste es el caso, paradigmáticamente, de los supuestos de homicidio y lesiones graves en el delito de genocidio, los crímenes contra la humanidad y los crímenes de guerra; discutible puede restar la cuestión de la penalidad, en particular por el hecho de 
Bascuñán - El derecho penal chileno ante el Estatuto de Roma

que no exista una solución concursal adecuada para los casos de unidad de acción con pluralidad masiva de resultados, salvo su incierta - y altamente controversialconsideración como concurso real; pero la congruencia de los ámbitos de punibilidad se encuentra fuera de toda duda;

(b) existe también un ámbito opuesto, en que el derecho penal chileno claramente no satisface el mandato de punición, como por ejemplo la instigación directa y pública a cometer genocidio, los supuestos de persecución y apartheid entre los crímenes contra la humanidad, y los supuestos de declaración en un tribunal de justicia de la suspensión o abolición de los derechos de los nacionales de la parte combatiente o enrolamiento de menores de edad, tratándose de los crímenes de guerra; respecto de estos ámbitos, la inadecuación del derecho penal chileno se encuentra asimismo fuera de toda duda;

(c) finalmente, existe una vasta e intrincada zona intermedia, en que las normas punitivas chilenas, si bien recogen el ámbito de punibilidad impuesto por el derecho penal internacional, lo hacen de un modo fragmentario, incierto y subordinado a condiciones ajenas a la finalidad de protección del derecho penal internacional; respecto de todo este ámbito, el examen de congruencia requiere revisar particularidades del derecho interno, sin que pueda afirmarse su total inadecuación, pero tampoco su satisfactoriedad.

Este resultado no es peculiar del derecho penal chileno. La comparación de cualquier Código Penal europeo del Siglo XIX —el chileno es una mezcla del Código español de 1850 y del Código belga de 1867 — arrojaría el mismo resultado.

\subsection{Opciones de técnica legislativa}

Una vez constatada la inadecuación del derecho penal interno a los requerimientos del derecho penal internacional, se abren en lo esencial dos caminos legislativos para remediarla:

(a) la recepción directa del derecho penal internacional convencional en el derecho penal interno, ya sea mediante el establecimiento de disposiciones que reproduzcan las disposiciones internacionales o de cláusulas de remisión a éstas;

(b) la recepción mediata del derecho penal internacional convencional, a través del establecimiento de disposiciones congruentes con el derecho penal internacional y a la vez con las categorías y conceptos del derecho penal interno.

La primera vía implica la satisfacción de los deberes de punición asumidos como deberes extremos de tipificación y configura en el derecho interno un régimen de tipificación paralelo al régimen común de tipificación. La segunda vía implica la satisfacción de los deberes de punición asumidos como deberes de incriminación y exige por lo tanto del legislador la realización de un trabajo de correlación del sentido normativo de ambos derechos convencionales.

No cabe duda que la primera opción evita el riesgo de inadecuación ante el derecho internacional, en el nivel de las disposiciones. Todo lo que se logra en el nivel de las disposiciones se pierde sin embargo en el nivel de las normas, ya que la configuración de un régimen paralelo, sujeto a conceptos y categorías sui generis respecto del derecho 
penal interno, implica la creación de un alto riesgo de incertidumbre en la aplicabilidad de una y otra regulación.

Sólo la contribución deliberada del legislador al esclarecimiento de las relaciones existentes entre los conceptos y categorías de uno y otro régimen punitivo puede disminuir para el órgano aplicador la complejidad inherente a la configuración de un tratamiento cualificado de un amplio ámbito de comportamientos ya típicos conforme al derecho penal interno. Ésa es la contribución que cabe esperar de una legislación penal fiel al ideal codificador.

Con todo, no puede desconocerse que existen ámbitos en los cuales el derecho penal internacional desempeña una función cuasi-constitutiva en virtud de la especificidad de sus definiciones. La regulación de los crímenes de guerra es el mejor ejemplo. Sin la definición de nociones como "personas protegidas", "bienes protegidos", "prisionero de guerra", "población civil", "conflicto armado" y "conflicto armado de carácter internacional" es impensable configurar la regulación de estos delitos, y carece de sentido intentar una "traducción" de estas definiciones a categorías del derecho interno, porque éstas son, o bien inexistentes o bien obsoletas.

De modo que la vía adecuada es una combinación, bajo un criterio definido de ponderación: mientras sean reconocibles en el derecho interno categorías correlativas a las del derecho internacional, debe adoptarse la recepción mediata del derecho internacional y consecuentemente debe efectuarse la contribución normativa de correlación entre unas y otras; en caso contrario, debe adoptarse la recepción directa del derecho internacional convencional.

La mayor virtud de optar preferentemente por el método de recepción mediata es que en esta tarea de mediación entre el derecho penal interno y el derecho penal internacional puede contribuirse a la solución de problemas que evidencian uno y otro. Me referiré primero a los problemas más importantes que presenta la Parte Especial del Código Penal chileno, para mencionar luego, de modo ejemplar, problemas de la tipificación de los crímenes internacionales en el Estatuto de Roma.

\subsection{Problemas fundamentales de la Parte Especial del Código Penal chileno}

Que el Código Penal chileno requiere una drástica revisión de su Parte Especial, es algo que no suscita mayores discrepancias. La adecuación al derecho penal internacional permite identificar ciertas áreas como prioritarias. Aparte de la regulación de los delitos contra el orden de la administración de justicia, que requiere ser introducida sistemáticamente por entero, estas áreas prioritarias en encuentran en:

(a) los delitos contra la incolumidad personal: la regulación de los delitos de lesiones requiere la simplificación de la tipificación de las lesiones gravísimas, incluyendo su tipificación como delito resultativo para eliminar de raíz la debatida cuestión de las restricciones a los medios o modos alternativos de comisión; requiere asimismo la adecuación de la penalidad de las lesiones simplemente graves y la introducción de la comisión peligrosa como hipótesis de lesión grave y como hipótesis calificada de lesión menos grave, es decir, calificaciones no por el resultado de lesión sino por el resultado de peligro de muerte o por el empleo de medios peligrosos (armas, veneno); finalmente, se 
Bascuñán - El derecho penal chileno ante el Estatuto de Roma

requiere una regulación explícita del maltrato de obra como delito doloso, incluyendo una regla especial para la producción de un resultado de lesiones imputable a imprudencia;

(b) los delitos contra la autonomía sexual: la reciente reforma de los delitos de violación, estupro y abuso sexual ha solucionado la mayor parte de las dificultades que presentaba el Código Penal originario; espera todavía una regulación coherente, sin embargo, el ámbito de los delitos de explotación sexual; particularmente importante en la configuración consistente del delito de proxenetismo transnacional, sobre la base de la explotación de la indefensión por la condición de extranjero;

(c) los delitos contra la libertad: de todos los grupos de delitos contra intereses personalísimos éste fue y sigue siendo con mucho el peor regulado en el Código Penal Chileno; la recepción mediata del derecho penal internacional exige perentoriamente una regulación consistente de los delitos de privación de libertad y coacción como horizonte de referencia; esto incluye la redefinición de los supuestos de secuestro, toma de rehén y sustracción de menores, así como de la fusión de las hipótesis de coacción violenta y amenazas condicionales en un solo tipo, con la diferenciación de estas últimas y las amenazas simples; demás está decirlo, la regulación satisfactoria de la coacción es una condición necesaria para enfrentar adecuadamente la cuestión de la regulación correcta del tratamiento médico no consentido y la experimentación humana no consentida;

Contando con una regulación satisfactoria de estos ámbitos de punibilidad puede configurarse con relativa facilidad una legislación especial de los crímenes contra la humanidad que descanse mayoritariamente en referencias al derecho penal interno. En todo lo aplicable, estas definiciones del núcleo de lo injusto son extensibles asimismo a los crímenes de guerra y a lo menos a ciertos supuestos del delito de genocidio.

\subsection{Problemas fundamentales de los crímenes de derecho internacional}

Como es evidente, la posición del legislador nacional respecto de la solución de problemas normativos referidos a la regulación de los crímenes internacionales es simétricamente opuesta a su posición respecto de la reforma de la Parte Especial interna. El margen de competencia del que dispone bajo los deberes de punición depende básicamente de dos consideraciones:

(a) del efecto extensivo o restrictivo del ámbito de punibilidad de la modificación intentada; en principio, la introducción de modificaciones con un efecto extensivo del ámbito de punibilidad de los crímenes internacionales no es contraria a los mandatos de punición; sólo en el caso de interpretarse el deber de punición como deber de tipificación y de redundar el efecto extensivo en una indiferenciación del ámbito típico exigido por ese deber, podría estimarse a ese efecto extensivo como un cumplimiento insatisfactorio del deber internacional; pero éste es un caso altamente improbable;

(b) tratándose de modificaciones con efecto restrictivo del ámbito de punibilidad, el margen de competencia depende obviamente de la interpretación de los deberes de punición como deberes de incriminación, deberes de tipificación moderada o deberes de tipificación extrema: en este preciso orden respectivo disminuye ese margen de competencia. La aceptación de la competencia del legislador interno para producir un efecto restrictivo del ámbito de punibilidad en la tipificación de los crímenes de derecho internacional exige asumir que los deberes internacionales de punición son deberes de 
incriminación o a lo más deberes moderados de tipificación. Asumiéndolo, se plantea la pregunta por la justificación de la producción de ese efecto restrictivo. Pues si la producción de un efecto extensivo del ámbito de punibilidad en principio no es inconsistente con los deberes de punición, la producción de un efecto restrictivo en principio sí lo es. ¿Qué razones podrían legitimar ese efecto?

Existen al menos dos razones de peso.

En primer lugar, debe notarse que el Estatuto de Roma concede a la Corte Penal Internacional un margen de discrecionalidad en la apreciación de la admisibilidad del caso en función de criterios de oportunidad. La Corte puede considerar el caso inadmisible si no tiene la gravedad suficiente para justificar su intervención (art. 17-1-d). El Estatuto admite, pues, que un caso formalmente constitutivo de crimen internacional pueda ser sin embargo materialmente insuficiente para gatillar la reacción punitiva de la Corte. Ésta es una premisa que el derecho interno no puede reproducir. La regulación de los delitos internacionales como crímenes o simples delitos de gravedad, en particular su tipificación como hipótesis especiales y calificadas de delitos comunes, excluye la aplicación a su respecto del principio de oportunidad para su prosecución. Luego, la definición del ámbito de punibilidad en el derecho interno debe ser tal que permita afirmar su considerable disvalor material de injusto. El logro de esta finalidad puede exigir una definición con efectos restrictivos en comparación con las definiciones del derecho internacional.

Es conocido el hecho que el principio de legalidad tiene en el derecho penal internacional un alcance distinto de la que tiene en el derecho penal interno de los sistemas jurídicos europeos continentales. Esto es manifiesto, por ejemplo, en el derecho internacional de los derechos humanos, donde no existe un principio de legalidad, sino más bien un principio de juridicidad, que no restringe el sistema de fuentes de las normas punitivas al derecho convencional y de ese modo erosiona la garantía de la irretroactividad. El derecho penal interno no puede desentenderse del principio de legalidad en la misma medida. Su satisfacción puede exigir también una definición con efectos restrictivos en comparación con las definiciones del derecho internacional.

Tres ejemplos servirán para ilustrar estas constelaciones de casos.

El primer ejemplo lo da la regulación del delito de genocidio. El Estatuto de Roma consolidó la definición convencional de este delito, que data de 1948. Yo soy de la opinión de que el concepto de genocidio, en los términos acuñados por la convención de las Naciones Unidas, que responden a la idea regulativa de Rafael Lemkin, es un concepto categorialmente inaceptable. Considero inaceptable como principio de política criminal que la protección de una identidad colectiva tenga mayor peso específico que la protección del interés individual en la supervivencia. Por cierto, no se me escapa el hecho de que se trata de identidades colectivas asociadas a la condición de minoría, y que la condición de minoría gatilla una situación de vulnerabilidad de los individuos que pertenecen a ella. Ése es un punto de vista político-criminal con el cual simpatizo. Pero aún reformulada de este modo la finalidad de protección de la norma punitiva del genocidio es evidente que se trata de una regulación discriminatoria. Es bien sabido que conforme a la definición convencional del genocidio fue genocida el exterminio nazi de judíos y gitanos, pero no el exterminio nazi de comunistas. La cuestión de la exclusión de los "grupos políticos" ha acompañado al delito de genocidio desde su génesis. Lo que no 
Bascuñán - El derecho penal chileno ante el Estatuto de Roma

se encuentra suficientemente esclarecido es que este efecto discriminatorio es inherente al concepto de grupo protegido en torno al cual se configura el delito de genocidio. La finalidad de protección de esta norma no abarca cualquier minoría vulnerable, sino sólo minorías cuya identidad es transgeneracional. Esto hace, por ejemplo, que las minorías sexuales queden inevitablemente excluidas de la protección brindada por la norma. Pues la identidad sexual disfuncional a la estructura heterosexual de la familia no es, por definición, transgeneracional. El exterminio nazi de homosexuales no puede ser considerado genocidio: no hay genus. La disolución del delito de genocidio en la regulación de los crímenes contra la humanidad es en mi opinión la única solución a este problema: una auténtica codificación del derecho penal internacional tendría que dar ese paso. Mientras tanto, el derecho penal interno puede al menos moverse hacia esa dirección, priorizando sistemáticamente la categoría de los crímenes contra la humanidad, y ampliando el catálogo de los grupos protegidos mediante una cláusula residual que ponga en evidencia el criterio transgeneracional de reconocimiento de la identidad colectiva. Ésta sería una modificación extensiva del ámbito de punibilidad.

Por otra parte, el delito de genocidio se encuentra estructurado sobre la concurrencia de un elemento subjetivo, como es el "propósito de destruir, en todo o en parte" alguno de los grupos protegidos. La clarificación de que se trata de una tendencia interna trascendente (überschiessende Innentenden $\approx$ ) y no de una tendencia interna intensificada (Tendens) elimina parte importante de las objeciones planteadas tradicionalmente a esta exigencia. La cuestión, sin embargo, radica en determinar si desde un punto de vista político-criminal basta con la pura subjetividad del agente para justificar la reacción punitiva intensificada que exige la calificación del hecho como genocidio. Excluidas para el derecho interno las consideraciones de oportunidad, en mi opinión es indispensable una intensificación de la tipificación objetiva del genocidio. En el Proyecto de los Elementos de los Crímenes se da a este respecto una pauta digna de ser tomada en consideración, al exigirse que el ataque genocida tenga lugar "en el contexto de una pauta manifiesta de conducta similar dirigida contra ese grupo" o que "haya podido por sí misma causar esa destrucción". Ambas alternativas responden a la necesidad de calificar objetivamente el ataque como una acción peligrosa para la supervivencia de la identidad de al menos parte considerable de los miembros del grupo. La explicitación de este elemento objetivo es, a mi juicio, indispensable en la tipificación del genocidio en el derecho interno. Ésta es una modificación restrictiva del ámbito de punibilidad.

El segundo ejemplo está dado por los delitos de persecución y apartheid, tal como son tipificados en el Estatuto de Roma. La "persecución" es definida como la "privación severa e intencional y contraria al derecho internacional de derechos fundamentales por razón de la identidad del grupo o colectividad" (art. $7^{\circ}-2-g$ ), y es considerada punible cuando se comete en conexión con otros crímenes del Estatuto (art. $7^{\circ}-1-\mathrm{h}$ ). El apartheid es definido como la realización de "actos inhumanos de carácter similar a (los actos constitutivos de crímenes contra la humanidad), cometidos en el contexto de un régimen de sistemática opresión y dominación de un grupo racial sobre otro y con la intención de mantener ese régimen". En ambos casos la tipificación no satisface el deber de determinación impuesto por el principio de legalidad: el primero es un tipo abierto, de antijuridicidad no sometida a selección de relevancia específicamente penal, y el segundo se encuentra construido sobre una cláusula analógica. Dado el carácter subordinado que ambos delitos tienen respecto de los demás crímenes internacionales (en el caso de la persecución) o de los demás crímenes contra la humanidad (en el caso del apartheid), desde el punto de vista de la complementariedad es, en mi opinión, suficiente que el 
derecho interno consagre el propósito o móvil discriminatorio como una circunstancia agravante con suficiente peso específico. La expresión del disvalor de la discriminación en la determinación de la pena evita el problema de la infracción al principio de legalidad.

Esta estrategia no es sin embargo posible, tratándose del tercer ejemplo, que corresponde a la más evidente infracción del Estatuto de Roma al deber de determinación. El art. $7^{\circ}$-k tipifica residualmente como crímenes contra la humanidad "otros actos inhumanos de carácter similar, cometidos intencionalmente causando gran sufrimiento o serio daño al cuerpo o a la salud mental o física”. La única forma de enfrentar esta dificultad en el derecho interno es tipificando esos otros actos conforme a las categorías de los delitos contra bienes jurídicos personalísimos, es decir, como lesiones, maltrato, experimentación y tratamiento médico no consentidos, abusos sexuales y aborto forzado. Aquí es evidente - pero ineludible- el efecto restrictivo del ámbito de punibilidad.

Finalmente, es importante tomar en consideración la existencia de casos en los cuales la tipificación específica tiene un valor puramente simbólico, en el sentido de que su prescindencia no produce efectos restrictivos en el ámbito de punibilidad, porque se trata de delitos específicos cuya configuración típica es fácilmente reducible a tipos básicos con los cuales se encuentran en relación de concurso aparente. La "esclavitud sexual" (art. $\left.7^{\circ}-1-\mathrm{g}\right)$, por ejemplo, no es más que una situación de concurso entre esclavitud (reducible ulteriormente a privación de libertad) y abuso sexual. El caso más conspicuo es, sin embargo, el de la desaparición forzada de personas (art. $7^{\circ}-1-1$ ), que a menos que se quiera infringir derechos fundamentales del acusado, no puede rebasar la condición de supuesto grave de privación de libertad por la concurrencia de una tendencia interna trascendente (überschiessende Innentendez), consistente en la intención de dejar al detenido al margen de la protección brindada por el régimen institucional de legitimación de la privación de libertad. Es mérito del Estatuto de Roma haber destacado este elemento (art. $7^{\circ}-2-1$ ), pero es su falta haber persistido en la injustificada tipificación autónoma de este supuesto de privación de libertad, mediante su asociación a la omisión de reconocer el hecho de la privación de libertad. Pues, como salta a la vista, si la privación de libertad fue en sí misma delictiva, ¿cómo podría fundamentar una agravación de la responsabilidad del autor su negativa a confesar la comisión del delito?

\section{PROBLEMAS BÁSICOS DE LA PARTE GENERAL}

Las relaciones de adecuación de la Parte General del derecho penal interno a la Parte General del derecho penal internacional, incluyendo los arts. 25 a 33 del Estatuto de Roma, es sin duda una cuestión exponencialmente más compleja que los problemas planteados por la Parte Especial. Pues en este caso lo que está en juego es la rivalidad de paradigmas alternativos de atribución de responsabilidad penal. La Parte General del derecho penal internacional es la cancha donde compiten las distintas matrices culturales de la teoría general del delito.

No es este el lugar oportuno para incursionar en esa intrincada red de perplejidades. A modo de sección final de mi contribución a este seminario, me basta con señalar tres cuestiones generales. 
Bascuñán - El derecho penal chileno ante el Estatuto de Roma

En primer lugar, que la Parte General del derecho penal chileno evidencia deficiencias que se hacen particularmente sensibles con ocasión de la recepción del derecho penal internacional. La comisión por omisión y el actuar en lugar de otro son los casos más conspicuos de lagunas regulativas.

En segundo lugar, que tratándose de la Parte General la recepción del derecho penal internacional admite una técnica de recepción directa, incluso por vía de remisión, a todas las reglas y principios relativos a la exención o exclusión de responsabilidad penal, es decir, a causas de justificación y de exculpación. Tratándose de las causas de justificación, esto me parece evidente: si el derecho internacional público es parte integrante del derecho interno, entonces el postulado de congruencia del derecho penal interno con la totalidad del ordenamiento jurídico comprende las normas de autorización del derecho internacional, incluso en el sentido de su efecto restrictivo de los supuestos de permisión del derecho interno. En mi opinión, también las causas de exculpación admiten y exigen una recepción directa. Ésta es sin duda la cuestión más sensible en la medida que el derecho internacional, particularmente el derecho humanitario, se caracteriza por la intensificación de sus estándares de exigibilidad en comparación con los estándares del derecho penal interno dirigidos al ciudadano medio. En mi opinión, es digna de controversia la cuestión de la racionalidad político-criminal de esos estándares intensificados de exigibilidad desde el punto de vista de las necesidades preventivas de la pena. Con todo, se trata de una controversia que debe darse en el nivel del derecho internacional. Una disminución de esos estándares no es legitimable como decisión puramente interna de política criminal.

Por el contrario, las reglas de la Parte General del derecho penal internacional que implican la extensión de los ámbitos de punibilidad, o sea, las reglas sobre coautoría, participación e iter criminis, no son susceptibles de recepción directa. Ellas deben someterse, en mi opinión, al mismo tratamiento que las normas de la Parte Especial. La excepción a este principio se encuentra, obviamente, en las reglas del derecho internacional público que configuran posiciones de garante, a las cuales tiene que entenderse referida la regulación de la comisión por omisión en este ámbito. El caso auténticamente difícil para este tratamiento diferenciado que propongo radica en los estándares de exigibilidad vinculados a la imputación subjetiva. Sobre este punto debo reconocer que aún no tengo una convicción formada. 